\title{
A Comparison of QRS Complexes Resulting From Unipolar and Bipolar Pacing: Implications for Pace-Mapping
}

\author{
ALAN H. KADISH, STEVE SCHMALTZ, and FRED MORADY \\ From the Division of Cardiology, Department of Internal Medicine, University of Michigan \\ Medical Center, Ann Arbor, Michigan
}

KADISH, A.H., ET AL.: A Comparison of QRS Complexes Resulting From Unipolar and Bipolar Pacing: Implications for Pace-Mapping. To examine differences in QRS configuration produced by bipolar versus unipolar pacing, 12-lead electrocardiograms recorded during bipolar (distal cathode) pacing with 5-and 10-mm interelectrode distances were compared to electrocardiograms recorded during unipolar cathodal pacing from the distal catheter pole. Pacing was performed at a cycle length of $500 \mathrm{msec}$ using each of the two bipolar configurations at current strengths equal to late diastolic threshold, twice threshold and $10 \mathrm{~mA}$. The pacing site was at the right ventricular apex in 15 patients and at various left ventricular locations in 14 patients. The electrocardiograms recorded during bipolar and unipolar pacing were compared by two independent observers for minor QRS configuration changes, major configuration changes and amplitude changes. Minor configuration differences between unipolar and bipolar pacing occurred occasionally when the interelectrode distance during bipolar pacing was $5 \mathrm{~mm}$ (mean \pm S.D. $0.5 \pm 1.2$ leads per electrocardiogram). However, when the interelectrode distance was $10 \mathrm{~mm}$, minor configuration differences were seen more commonly $(1.3 \pm 2.0$ leads per electrocardiogram; $P<0.05$ vs $5-\mathrm{mm}$ distance). Major configuration differences were uncommon with either configuration at all current strengths. Pacing at $10 \mathrm{~mA}$ produced a larger number of configuration differences than pacing at either threshold or twice threshold $(P<0.05)$. Amplitude differences were seen in a mean of $1.9 \pm$ 2.1 leads per electrocardiogram with the $5-\mathrm{mm}$ interelectrode distance and a mean of $2.9 \pm 2.1$ leads using the $10-\mathrm{mm}$ interelectrode distance $(P<0.05)$. In conclusion: $(1)$ bipolar ventricular pacing can result in QRS complexes that are different from those obtained with unipolar pacing at the same catheter location, presumably due to an anodal contribution during bipolar pacing; (2) increasing the interelectrode distance and stimulus intensity increases these differences; and (3) because the proximal electrode's contribution to depolarization can alter the QRS configuration during pacing in a variable way, the use of bipolar pace-mapping to localize sites of origin of ventricular tachycardia may result in less spatial resolution than unipolar pace-mapping. (PACE, Vol. 14, May, Part I 1991)

ventricular pacing, ventricular tachycardia, mapping, pace-mapping

\section{Introduction}

Examination of the QRS configuration during

Supported in part by Grant 5M01-RR00042-25 from the National Institute of Health, Bethesda, Maryland.

Dr. Kadish is a recipient of an NIH First Award Number HL40667.

Address for reprints: Alan H. Kadish, M.D., Northwestern Memorial Hospital, 250 E. Superior Street, Suite 524, Chicago, IL 60611. Fax: (312)908-6003.

Received December 10, 1990; revision January 31, 1991; accepted February 25, 1991. ventricular pacing or pace-mapping has been one of several methods used to localize the site of origin of ventricular tachycardia. ${ }^{2-5}$ Although unipolar and bipolar pace-mapping have been used, they have not been carefully compared. We have demonstrated $^{6}$ that comparison of QRS complexes recorded during unipolar pacing generally can discriminate ventricular sites that are within 5 
$\mathrm{mm}$ of each other. However, the discriminating ability of bipolar pacing has not been quantitated. Whereas bipolar pacing has the potential advantage of producing a smaller stimulus artifact than unipolar pacing, an anodal contribution to ventricular stimulation during bipolar pacing ${ }^{7}$ could shift the site of stimulus origin away from the catheter tip towards the more proximal anode, thereby decreasing the accuracy of the pace map. Because the interelectrode distance used during bipolar pacing in the clinical electrophysiology laboratory commonly is 5 or $10 \mathrm{~mm}$, a change in the effective site of stimulation due to an anodal contribution could potentially affect the spatial information provided by bipolar pacing.

The goal of this study was to examine the electrocardiograms obtained during bipolar pacing using interelectrode distances of 5 and $10 \mathrm{~mm}$ to electrocardiograms obtained during unipolar pacing in order to compare the potential value of unipolar and bipolar pace-mapping.

\section{Methods}

\section{Study Design}

Unipolar cathodal pacing from the distal pole of a catheter at threshold was used to simulate the site of origin of ventricular tachycardia. Bipolar pacing with the same catheter at the same location was performed using the first and second as well as the first and third poles of a quadripolar catheter that has an interelectrode distance of $5 \mathrm{~mm}$. The distal catheter pole served as the cathode. Stimulus intensities of threshold, twice threshold, and $10 \mathrm{~mA}$ were used in each of these two pacing configurations (5- and 10-mm interelectrode distance) for a total of six 12-lead electrocardiograms. The differences in QRS configuration and amplitude between electrocardiograms obtained during unipolar and bipolar pacing were evaluated.

\section{Patient Population}

Inclusion criteria for patients were:

(1) Electrophysiology study in the absence of antiarrhythmic medication.

(2) Sinus rhythm $<110$ beats/min.

(3) The ability to obtain unipolar stimulation thresholds from the three distal poles of the cath- eter of $<2 \mathrm{~mA}$ from the right ventricle or $<10 \mathrm{~mA}$ in the left ventricle. The threshold requirement was designed to limit variability in the position of the proximal electrodes, which might contribute to activation during bipolar pacing.

Unipolar pacing was used to simulate the site of origin of ventricular tachycardia and patients were not selected for the presence of spontaneous ventricular tachycardia. Right ventricular pacing was performed in 15 consecutive patients who met these three criteria. Four patients were excluded because they did not meet criterion number 3. Left ventricular pacing was performed in 14 consecutive patients who had a clinical indication for left ventricular catheterization and who met these three criteria. Six patients were excluded because they did not meet criterion number 3 .

The subjects of the study were 19 men and 10 women whose mean age was $58 \pm 12$ years. The mean ejection fraction was $0.47 \pm 0.16$ in 22 patients in whom this measurement was available. Nine patients had no heart disease, 11 had coronary artery disease, and nine had cardiomyopathy (dilated in five, and hypertensive hypertrophic in four). Eleven of the 14 patients in whom left ventricular pacing was performed had either coronary artery disease or cardiomyọpathy. All patients included in the study underwent clinically indicated electrophysiological studies. The study conforms to the principles in the Declaration of Helsinki and informed consent was obtained.

\section{Study Protocol}

After informed consent was obtained, electrophysiological studies were performed in the fasting and unsedated state. One or more 6 French quadripolar catheters (USCI, Billerica, MA, USA) were inserted through a femoral vein or femoral artery and advanced to the right or left ventricle, as clinically indicated. A 6 French quadripolar catheter (USCI) with a $5-\mathrm{mm}$ interelectrode distance was used for pacing. In the right ventricle, catheters were positioned in the apex. In the left ventricle, catheters were positioned in an area where the endocardial electrogram was abnormal in the 11 patients with heart disease. The left ventricular pacing site was septal in four patients, inferolateral in five, and anterior in five. A Bloom DTU 210 stimulator (Bloom Associates, Ltd., Nor- 
beth, PA, USA) with a constant current stimulus isolation unit was used for pacing. A SiemensElema Mingograf 7 recorder (Siemens-Elema, Solna, Sweden) was used to record 12 lead electrocardiograms six leads at a time at a paper speed of $25 \mathrm{~mm} /$ second.

The late diastolic threshold was determined in an incremental fashion using steps of $0.1 \mathrm{~mA}$. Unipolar pacing from the catheter tip was performed at threshold using a pulse width of $2 \mathrm{msec}$. Bipolar pacing was performed with a pulse width of $2 \mathrm{msec}$ at current strengths of threshold, twice threshold, and $10 \mathrm{~mA}$. For unipolar pacing, a catheter in the inferior vena cava was used as the indifferent electrode. ${ }^{8}$ Electrocardiograms were recorded during ventricular pacing at a cycle length of $500 \mathrm{msec}$. Six seconds of recording time was allowed for each group of leads. Electrocardiograms were amplified and displayed at a gain of $1 \mathrm{mV} / \mathrm{cm}$ and filtered at $.05-1,000 \mathrm{~Hz}$. A total of six electrocardiograms were obtained during bipolar pacing (three stimulus intensities at each of two interelectrode distances). Table I shows the pacing configuration for the one unipolar and six bipolar electrocardiograms.

Local electrograms were recorded at a paper speed of $100 \mathrm{~mm} / \mathrm{second}$ and an amplitude of 10 $80 \mathrm{~mm} / \mathrm{mV}$ using each of the three pacing configurations (one unipolar and two bipolar). Local electrograms were filtered at $50-500 \mathrm{~Hz}$. Electrogram amplitude was determined to the nearest 0.1 $\mathrm{mV}$ and electrogram duration to the nearest 5 msec. Electrogram duration was determined from a fixed gain recording $(10 \mathrm{~mm} / \mathrm{mV}) .{ }^{9}$ Electrocar-

Table I.

Description of ECGs

\begin{tabular}{cccc}
\hline ECG & $\begin{array}{c}\text { Interelec- } \\
\text { trode } \\
\text { Number }\end{array}$ & $\begin{array}{c}\text { Pacing } \\
\text { Distance } \\
\text { (mm) }\end{array}$ & $\begin{array}{c}\text { Stimulus } \\
\text { Intensity }\end{array}$ \\
\hline 1 & Unipolar & 0 & Threshold \\
2 & Bipolar & 5 & Threshold \\
3 & Bipolar & 5 & Twice Threshold \\
4 & Bipolar & 5 & $10 \mathrm{~mA}$ \\
5 & Bipolar & 10 & Threshold \\
6 & Bipolar & 10 & Twice Threshold \\
7 & Bipolar & 10 & 10 mA \\
\hline
\end{tabular}

diograms obtained with unipolar pacing from the same patient population were also used in a related study of the spatial resolution of unipolar pacing. ${ }^{6}$

\section{Electrocardiogram Analysis}

Criteria for analysis of electrocardiogram amplitude and configuration have been previously described. ${ }^{6}$ Electrocardiograms obtained during bipolar pacing were compared to that obtained during unipolar pacing. Electrocardiograms were analyzed independently by two observers. Differences between the observers were resolved by consensus. Electrocardiograms were examined for amplitude and configuration differences according to the following criteria:

\section{Amplitude}

Spontaneous variability in QRS amplitude can occur secondary to respiratory variation or other factors. We have previously shown that variations in QRS amplitude of $>2 \mathrm{mV}$ are unlikely to be due to spontaneous variability and thus, changes of $2 \mathrm{mV}$ or more were felt to represent true changes in QRS amplitude. ${ }^{6}$

\section{Configuration}

Specific configuration and criteria were defined to minimize subjectivity in the analysis of QRS configuration. All configuration comparisons were made in reference to electrocardiogram 1pacing from the distal electrode in a unipolar cathodal fashion. For each of the six remaining electrocardiograms, each lead was graded independently by two observers as: (1) no change, (2) minor configuration change, or (3) major configuration change.

Minor configuration differences consisted of one of the following:

(a) Appearance or disappearance of a notch.

(b) Appearance or disappearance of a Q, R, or $S$ wave that was $<25 \%$ of the peak-to-peak QRS amplitude.

(c) A change was said to occur only if the ratio of the amplitude of the individual component to the total QRS amplitude changed by $>25 \%$ but $<50 \%$. 
(d) A change in the shape of a major component-either a marked change in slope upstroke or a change in the configuration of the peak.

Major configuration differences consisted of the following:

(a) Appearance or disappearance of a component that was $>50 \%$ of the QRS amplitude.

(b) A change in the amplitude of a component of the QRS complex of $>50 \%$ of the total QRS amplitude.

(c) Two or more minor configuration differences.

If the QRS configuration varied from beat-tobeat in a particular lead being compared, the two leads were not considered to be different if any one QRS complex in each of the recordings was similar.

\section{Data Analysis}

Data are expressed as mean \pm standard deviation. As previously mentioned, the electrocardiograms obtained during bipolar pacing (electrocardiograms 2-7) were compared to those obtained during unipolar pacing. Differences between electrocardiograms were expressed in two ways: the mean number of leads per electrocardiogram that showed a difference, and the number of patients who had one or more leads that showed a difference. In general, the square roots of the data were analyzed as opposed to the raw data to control for the skewness in the raw data distributions. Differences between QRS configuration and amplitude between the right and left ventricular pacing sites (RV vs $L V$ ) were evaluated by Student's t-test, while differences between the three heart disease groups (no heart disease, coronary artery disease, and cardiomyopathy) were examined using analysis of variance. Differences in QRS configuration and amplitude using different electrode configurations and different current strengths were compared using repeated measures analysis of variance or paired $t$-tests when appropriate. Multiple comparisons were performed using Fisher's least significant difference procedure. A P value of $<0.05$ was considered significant.

\section{Results \\ Thresholds and Electrograms}

Bipolar pacing thresholds and electrogram amplitude and duration did not differ between the 5- and 10-mm interelectrode distances. The mean bipolar pacing threshold was $0.56 \pm 0.21 \mathrm{~mA}$ with the 5-mm interelectrode distance, and $0.56 \pm 0.19$ $\mathrm{mA}$ with the $10-\mathrm{mm}$ interelectrode distance. The mean endocardial electrogram amplitude was 7.0 $\pm 4.8 \mathrm{mV}$ with the 5 - $\mathrm{mm}$ interelectrode distance, and $7.4 \pm 4.4 \mathrm{mV}$ with the $10-\mathrm{mm}$ interelectrode distance. The mean endocardial electrogram durations were $46 \pm 16$ and $55 \pm 16 \mathrm{msec}$ with the 5 - and $10-\mathrm{mm}$ interelectrode distances, respectively. The pacing threshold and electrogram amplitude with the unipolar configuration $(0.58 \pm$ $0.29 \mathrm{~mA}$ and $6.6 \pm 3.8 \mathrm{mV}$ ) were similar to the bipolar configurations. However, the unipolar electrogram duration $(71 \pm 25 \mathrm{msec})$ was significantly longer than the bipolar electrogram durations $(P<0.05)$.

\section{Analysis of Configuration}

A total of 2,088 leads (six 12-lead electrocardiograms in each of 29 patients) were analyzed. The two observers agreed in $90 \%$ of cases. There were $146(7 \%)$ disagreements between minor and no differences, $63(3 \%)$ disagreements between minor and major differences, and nine $(0.4 \%)$ disagreements between no major differences.

As expected, the stimulus artifact during bipolar pacing was smaller than during unipolar pacing at the same current strength (Fig. 1). Neither unipolar pacing at threshold nor bipolar pacing at up to $10 \mathrm{~mA}$ was associated with a stimulus artifact, which obscured the initial portion of the QRS complex.

\section{Configuration Differences}

Bipolar pacing resulted in occasional configuration differences compared to unipolar pacing. Figure 1 shows an example of differences between electrocardiograms recorded during unipolar pacing, bipolar pacing with an interelectrode distance of $5 \mathrm{~mm}$, and bipolar pacing with an interelectrode distance of $10 \mathrm{~mA}$. The evaluation of individual leads contained in Figure 1 is shown in Table II. The types of configuration differences and presence of amplitude differences seen in the individual leads are shown in Table II 


\section{EKG NUMBER}

2

V2

V3

V4

V5

V6

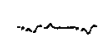

$a r-a r$

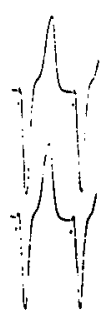

v<smiles>CCCCC[Te]</smiles>
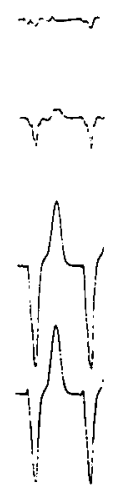

$-\wedge$<smiles>C1CC2CCC(C1)C2</smiles>

$\checkmark v$
3
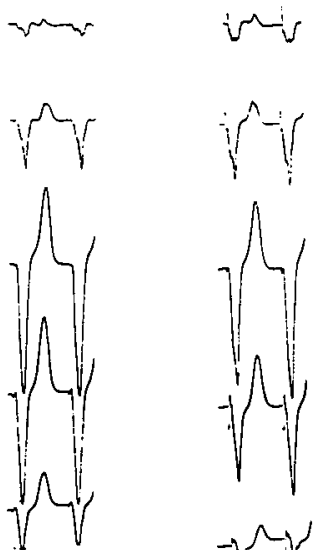

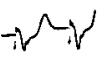

$r v$

4
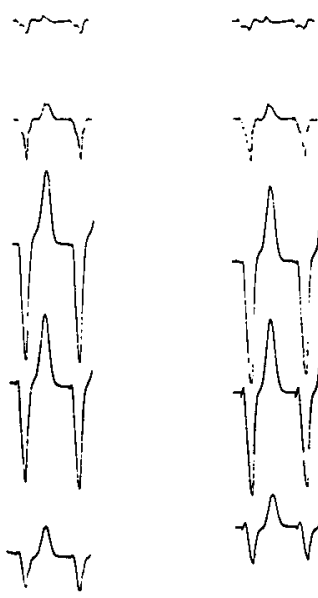

$\overbrace{i}^{\prime}$

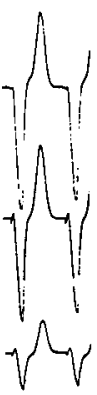

$\sim$

purm
6

Figure 1. Example of six simultaneously recorded leads from electrocardiograms 1-7. Note that the stimulus artifact in electrocardiogram 1 (unipolar pacing at threshold) is larger than that in electrocardiograms 2 or 5 (bipolar pacing at threshold). However, the stimulus artifact during bipolar pacing at $10 \mathrm{~mA}$ (electrocardiograms 4 and 7) is similar in amplitude to the unipolar stimulus artifact. Several leads show amplitude and configuration changes between electrocardiogram 1 and electrocardiograms 2-7. A complete description of the grading of amplitude and configuration differences in this patient's chest leads is shown in Table I.

and correspond to the types of changes described in the Methods section.

Overall, minor configuration differences occurred in a mean of $0.5 \pm 1.2$ leads per electrocardiogram when the interelectrode distance was $5 \mathrm{~mm}$ (data from all three current strengths pooled). However, when the interelectrode distance was $10 \mathrm{~mm}$, minor configuration differences were seen more commonly $(1.3 \pm 2.0$ leads per electrocardiogram; $\mathrm{P}<0.05$ vs $5-\mathrm{mm}$ distance). Data for the mean number of leads showing a minor configuration difference are shown in Table III and the number of patients with one or more leads showing a difference in Table IV. Four of 29 patients demonstrated configuration differences when pacing with a $5-\mathrm{mm}$ interelectrode distance at threshold was compared to unipolar pacing. Major configuration differences were uncommon with either configuration at any of the current strengths used (Table III). The number of configuration differences was highly variable from patient-to-patient. Although major configuration differences were uncommon, occasional patients showed a number of such differences (Fig. 1).

The pacing current strength had a significant effect on the number of configuration differences seen with bipolar pacing. Although the number of these differences (all interelectrode distances pooled) was similar during pacing at threshold and twice threshold $(0.6 \pm 1.5$ and $0.8 \pm 1.6)$, at a current strength of $10 \mathrm{~mA}$ the mean number of leads showing a configuration difference was higher $(1.4 \pm 1.9 ; \mathrm{P}<0.05$ vs threshold and twice threshold). Configuration differences were equally common in the limb and chest leads (Table III). 
Table II.

Evaluation of the Chest Leads Shown in Figure 1

\begin{tabular}{|c|c|c|c|c|c|c|}
\hline \multirow[b]{2}{*}{ Lead } & \multicolumn{6}{|c|}{ EKG Number } \\
\hline & 2 & 3 & 4 & 5 & 6 & 7 \\
\hline \multicolumn{7}{|c|}{ Morphology Differences } \\
\hline$v_{1}$ & None & None & Major (3) & None & Major (3) & Major (3) \\
\hline$V_{2}$ & None & None & Minor (1) & None & Major (3) & Minor (1) \\
\hline$v_{3}$ & None & None & None & None & Major (3) & None \\
\hline$v_{4}$ & None & None & None & None & Major (3) & None \\
\hline$V_{5}$ & None & None & Minor (1) & None & Major (3) & Major (3) \\
\hline$V_{6}$ & None & None & Major (2) & Minor (1) & Minor (1) & Major (2) \\
\hline \multicolumn{7}{|c|}{ Amplitude Differences } \\
\hline$V_{1}$ & - & - & + & - & - & + \\
\hline$V_{2}$ & - & + & + & + & + & + \\
\hline$V_{3}$ & - & + & + & + & + & + \\
\hline$v_{4}$ & - & + & 一 & - & - & - \\
\hline$V_{5}$ & - & - & $\dot{-}$ & - & - & - \\
\hline$V_{6}$ & - & - & - & - & - & - \\
\hline
\end{tabular}

Numbers in parentheses indicate the type of morphology changes seen; $+=$ Amplitude difference of more than $2 \mathrm{mV}$ seen in that lead.

\section{Amplitude Differences}

Amplitude differences between electrocardiograms obtained during bipolar and unipolar pacing were seen more frequently than configuration differences. Table $\mathrm{V}$ shows the mean number of leads per patient with a difference, and Table VI the number of patients with at least one lead different compared to unipolar pacing. A mean of 1.9 \pm 2.1 leads showed an amplitude difference from control when the bipolar pacing interelectrode distance was $5 \mathrm{~mm}$ (all interelectrode distances pooled) compared to a mean of $2.9 \pm 2.1$ leads when the interelectrode distance was $10 \mathrm{~mm}(\mathrm{P}<$ 0.001). As with configuration differences, amplitude differences were more prevalent at the higher stimulation currents (Tables V and VI). When pacing at $10 \mathrm{~mA}, 23$ of $29(80 \%)$ patients had at least

Table III.

Mean Number of Leads Per ECG Showing a Configuration Difference During Bipolar Pacing Compared to Unipolar Pacing

\begin{tabular}{|c|c|c|c|c|c|c|c|c|c|}
\hline \multirow[b]{2}{*}{$\begin{array}{c}\text { ECG } \\
\# \\
\end{array}$} & \multicolumn{3}{|c|}{ Minor Differences } & \multicolumn{3}{|c|}{ Major Differences } & \multicolumn{3}{|c|}{ Any Configuration Differences } \\
\hline & $\begin{array}{l}\text { Limb } \\
\text { Leads }\end{array}$ & $\begin{array}{l}\text { Chest } \\
\text { Leads }\end{array}$ & $\begin{array}{c}12 \\
\text { Leads }\end{array}$ & $\begin{array}{l}\text { Limb } \\
\text { Leads }\end{array}$ & $\begin{array}{l}\text { Chest } \\
\text { Leads }\end{array}$ & $\begin{array}{c}12 \\
\text { Leads }\end{array}$ & $\begin{array}{l}\text { Limb } \\
\text { Leads }\end{array}$ & $\begin{array}{l}\text { Chest } \\
\text { Leads }\end{array}$ & $\begin{array}{c}12 \\
\text { Leads }\end{array}$ \\
\hline 2 & $0.3 \pm 0.9$ & $0.2 \pm 0.7$ & $0.5 \pm 1.4$ & - & - & - & $0.3 \pm 0.9$ & $0.2 \pm 0.7$ & $0.3 \pm 1.1$ \\
\hline 3 & $0.2 \pm 0.8$ & $0.2 \pm 0.5$ & $0.4 \pm 1.0$ & - & - & - & $0.2 \pm 0.8$ & $0.2 \pm 0.5$ & $0.4 \pm 1.0$ \\
\hline 4 & $0.4 \pm 0.9$ & $0.4 \pm 0.8$ & $0.9 \pm 1.4$ & $0.0 \pm 0.1$ & $0.1 \pm 0.4$ & $0.1 \pm 0.4$ & $0.5 \pm 1.0$ & $0.5 \pm 0.9$ & $1.0 \pm 1.5$ \\
\hline 5 & $0.3 \pm 0.9$ & $0.4 \pm 1.0$ & $0.7 \pm 1.8$ & - & $0.0 \pm 0.2$ & $0.0 \pm 0.2$ & $0.3 \pm 0.9$ & $0.4 \pm 1.1$ & $0.8 \pm 1.8$ \\
\hline 6 & $0.4 \pm 0.9$ & $0.8 \pm 1.4$ & $1.2 \pm 2.0$ & - & $0.0 \pm 0.2$ & $0.0 \pm 0.2$ & $0.4 \pm 0.9$ & $0.8 \pm 1.4$ & $1.2 \pm 2.0$ \\
\hline 7 & $0.9 \pm 1.4$ & $1.0 \pm 1.4$ & $2.0 \pm 2.2$ & - & $0.1 \pm 0.4$ & $0.1 \pm 0.4$ & $0.9 \pm 1.4$ & $1.1 \pm 1.4$ & $2.0 \pm 2.2$ \\
\hline
\end{tabular}


Table IV.

Number of Patients with One or More Leads Showing a Morphology Difference During Bipolar Pacing Compared to Unipolar Pacing

\begin{tabular}{|c|c|c|c|c|c|c|c|c|c|}
\hline \multirow[b]{2}{*}{$\begin{array}{c}\text { ECG } \\
\#\end{array}$} & \multicolumn{3}{|c|}{ Minor } & \multicolumn{3}{|c|}{ Major } & \multicolumn{3}{|c|}{ Any Configuration Differences } \\
\hline & $\begin{array}{l}\text { Limb } \\
\text { Leads }\end{array}$ & $\begin{array}{l}\text { Chest } \\
\text { Leads }\end{array}$ & $\begin{array}{c}12 \\
\text { Leads }\end{array}$ & $\begin{array}{l}\text { Limb } \\
\text { Leads }\end{array}$ & $\begin{array}{l}\text { Chest } \\
\text { Leads }\end{array}$ & $\begin{array}{c}12 \\
\text { Leads }\end{array}$ & $\begin{array}{l}\text { Limb } \\
\text { Leads }\end{array}$ & $\begin{array}{l}\text { Chest } \\
\text { Leads }\end{array}$ & $\begin{array}{c}12 \\
\text { Leads } \\
\end{array}$ \\
\hline 2 & 5 & 4 & 4 & 0 & 0 & 0 & 4 & 3 & 4 \\
\hline 3 & 5 & 5 & 7 & 0 & 0 & 0 & 4 & 4 & 7 \\
\hline 4 & 9 & 9 & 13 & 1 & 1 & 2 & 8 & 9 & 13 \\
\hline 5 & 6 & 6 & 8 & 0 & 1 & 1 & 5 & 5 & 8 \\
\hline 6 & 7 & 12 & 13 & 0 & 1 & 1 & 6 & 10 & 13 \\
\hline 7 & 12 & 14 & 19 & 0 & 19 & 0 & 12 & 19 & 27 \\
\hline
\end{tabular}

one lead with an amplitude difference when using a 5 -mm interelectrode distance, and 27 of $29(93 \%)$ when the interelectrode distance was $10 \mathrm{~mm}$. Amplitude differences (all pacing current strengths and interelectrode distances pooled) were more common in the limb (mean $1.4 \pm 1.0$ leads per patient) than the chest leads (mean $1.0 \pm 1.1$ leads per patient; $(\mathrm{P}<0.05)$.

\section{Amplitude or Configuration Differences}

The mean number of leads showing either a configuration or amplitude difference during bipolar pacing compared to unipolar pacing is shown in Table $\mathrm{V}$ and the number of patients with at least one lead showing a configuration or amplitude difference from unipolar pacing in Table VI. Electrocardiograms recorded during bipolar pacing frequently differed from those recorded during unipolar pacing. More than half the patients had at least one lead with a difference compared to unipolar pacing (Table VI). The mean number of leads with a difference ranged from 2.0 \pm 2.5 for electrocardiogram 2 to $5.2 \pm 2.9$ for electrocardiogram 7 .

\section{Effects of Pacing Site and Heart Disease}

The number of leads with configuration differences was similar during right and left ventricular pacing. Amplitude differences were more common, during right ventricular pacing. This difference reached significance only for electrocardiograms 4 and $7(\mathrm{P}<0.05)$. Underlying heart disease had no effect on configuration differences but did have an effect on amplitude differences. Patients with coronary artery disease had fewer amplitude differences than did patients with either

\section{Table V.}

Mean Number of Leads Per ECG Showing an Amplitude Difference or Any (Configuration or Amplitude) Difference During Bipolar Pacing Compared to Unipolar Pacing

\begin{tabular}{|c|c|c|c|c|c|c|}
\hline \multirow[b]{2}{*}{$\begin{array}{c}\text { ECG } \\
\#\end{array}$} & \multicolumn{3}{|c|}{ Amplitude Difference } & \multicolumn{3}{|c|}{$\begin{array}{l}\text { Any Contiguration or Amplitude } \\
\text { Difference }\end{array}$} \\
\hline & $\begin{array}{l}\text { Limb } \\
\text { Leads }\end{array}$ & $\begin{array}{l}\text { Chest } \\
\text { Leads }\end{array}$ & $\begin{array}{c}12 \\
\text { Leads }\end{array}$ & $\begin{array}{l}\text { Limb } \\
\text { Leads }\end{array}$ & $\begin{array}{l}\text { Chest } \\
\text { Leads }\end{array}$ & $\begin{array}{c}12 \\
\text { Leads }\end{array}$ \\
\hline 2 & $0.6 \pm 1.1$ & $1.1 \pm 1.3$ & $1.8 \pm 2.1$ & $1.3 \pm 1.3$ & $0.9 \pm 1.4$ & $2.0 \pm 2.5$ \\
\hline 3 & $0.6 \pm 1.2$ & $1.1 \pm 1.3$ & $1.6 \pm 2.4$ & $1.3 \pm 1.3$ & $0.9 \pm 1.7$ & $2.1 \pm 2.6$ \\
\hline 4 & $1.0 \pm 1.4$ & $1.2 \pm 1.2$ & $2.2 \pm 2.4$ & $1.8 \pm 1.6$ & $1.3 \pm 1.6$ & $3.1 \pm 3.0$ \\
\hline 5 & $0.7 \pm 1.2$ & $1.3 \pm 1.7$ & $2.0 \pm 2.4$ & $1.5 \pm 1.7$ & $1.0 \pm 1.5$ & $2.4 \pm 3.0$ \\
\hline 6 & $1.3 \pm 1.7$ & $1.7 \pm 1.3$ & $3.0 \pm 2.5$ & $2.3 \pm 1.7$ & $1.4 \pm 1.8$ & $3.7 \pm 2.9$ \\
\hline 7 & $1.8 \pm 1.5$ & $2.0 \pm 1.4$ & $3.8 \pm 2.4$ & $2.9 \pm 1.8$ & $2.4 \pm 1.5$ & $5.2 \pm 2.9$ \\
\hline
\end{tabular}


Table VI.

Mean Number of Leads Per ECG Showing an Amplitude Difference or Any (Configuration or Amplitude) Difference During Bipolar Pacing Compared to Unipolar Pacing

\begin{tabular}{|c|c|c|c|c|c|c|}
\hline \multirow[b]{2}{*}{$\begin{array}{c}\text { ECG } \\
\#\end{array}$} & \multicolumn{3}{|c|}{ Amplitude Difference } & \multicolumn{3}{|c|}{$\begin{array}{l}\text { Any Configuration or Amplitude } \\
\text { Difference }\end{array}$} \\
\hline & $\begin{array}{l}\text { Limb } \\
\text { Leads }\end{array}$ & $\begin{array}{l}\text { Chest } \\
\text { Leads }\end{array}$ & $\begin{array}{c}12 \\
\text { Leads }\end{array}$ & $\begin{array}{l}\text { Limb } \\
\text { Leads }\end{array}$ & $\begin{array}{l}\text { Chest } \\
\text { Leads }\end{array}$ & $\begin{array}{c}12 \\
\text { Leads }\end{array}$ \\
\hline 2 & 12 & 16 & 19 & 17 & 14 & 19 \\
\hline 3 & 7 & 16 & 18 & 19 & 11 & 22 \\
\hline 4 & 14 & 20 & 22 & 22 & 16 & 23 \\
\hline 5 & 10 & 16 & 16 & 17 & 13 & 17 \\
\hline 6 & 16 & 24 & 28 & 26 & 19 & 28 \\
\hline 7 & 20 & 25 & 27 & 27 & 25 & 27 \\
\hline
\end{tabular}

no heart disease or those with cardiomyopathy ( $\mathrm{P}$ $<0.05$ for electrocardiogram 7).

\section{Discussion}

QRS complexes recorded during bipolar pacing were found to have amplitude and configuration differences when compared to unipolar pacing at the same catheter location. These differences were more common with a 10- than 5$\mathrm{mm}$ interelectrode difference and more common when pacing at $10 \mathrm{~mA}$ than at threshold or twice threshold. The number of differences was highly variable from patient-to-patient. The most likely explanation for the differences in QRS configuration and amplitude is that the anode contributes to ventricular activation during bipolar pacing. The variable shift in the effective site of stimulation away from the catheter tip decreases the degree of spatial resolution provided by bipolar pacing and suggests that unipolar pace-mapping may be superior to bipolar pace-mapping for localizing the site of origin of ventricular tachycardia.

\section{Prior Studies on Pace-Mapping}

Josephson, et al. ${ }^{1}$ compared bipolar pace maps in 12 patients with the patients' ventricular tachycardia. They noted that the 12-lead electrocardiographic configuration could either be "similar" or "different." However, the pace maps were evaluated only in a qualitative fashion, strict criteria for evaluating the QRS complexes during pacing were not developed, and only bipolar pac- ing was used. ${ }^{1}$ Other studies have used liberal criteria such as axis shift of $<45^{\circ}$ to classify pace maps as similar. ${ }^{10}$

A prior study examined the effects of current strength on the QRS complexes produced by bipolar pacing. Altering the current strength during bipolar pacing with permanent pacemaker leads was shown to affect the QRS configuration, suggesting that several factors may affect electrocardiograms obtained during bipolar pacing. ${ }^{11}$

We have examined the spatial resolution of unipolar pace-mapping in another study. ${ }^{6}$ If only major configuration differences are searched for, electrocardiograms obtained during pacing from sites as far as $15 \mathrm{~mm}$ apart could be considered "similar." However, if minor configuration differences and amplitude changes were searched for, almost all electrocardiograms obtained during pacing from sites as close as $\mathbf{5} \mathbf{~ m m}$ demonstrated some difference.

\section{Anodal Stimulation and Anodal Contribution During Bipolar Pacing}

It has been previously demonstrated that anodal stimulation can produce excitation of cardiac tissue. Dekker ${ }^{12}$ suggested that anodal excitation occurred at the onset of the pulse ("make") but had a longer latency than cathodal stimulation. Frazier et al., ${ }^{13}$ agreed with these conclusions at least at stimulation currents of $<5 \mathrm{~mA}$ and found that stimulation thresholds were higher for anodal stimulation than cathodal stimulation. Stevenson et al., ${ }^{7}$ confirmed that the anode can contribute to ventricular excitation during bipolar programmed 
electrical stimulation. Thus, excitation of ventricular myocardium by the proximal anode during bipolar pacing occurs and may be more prominent at higher pacing current strengths. In this study, the distal electrode was used as the cathode during unipolar and bipolar pacing. Thus, any differences between unipolar and bipolar pacing were most likely due to the contribution of the proximal anode to ventricular stimulation during bipolar pacing. Activation at the anode may coexist or merge with distal cathodal excitation, shifting the effective site of stimulation away from the catheter tip and towards the proximal electrodes.

\section{Electrocardiograms Obtained During Bipolar Pacing}

Electrocardiograms obtained during bipolar pacing with interelectrode distances of 5 and 10 mm occasionally demonstrated configuration and amplitude differences from the electrocardiogram obtained with unipolar pacing, suggesting that the site of effective stimulation was shifted by an anodal contribution. This shift occurred away from the catheter tip towards the proximal electrode and was influenced by the interelectrode distance. Electrocardiograms obtained with a $10-\mathrm{mm}$ interelectrode distance showed more differences from unipolar pacing than when the interelectrode distance was $5 \mathrm{~mm}$. We have previously shown that unipolar pacing from sites as close as $\mathbf{5 m m}$ apart could show such differences, suggesting that this degree of shift in the site of stimulation was adequate to account for the differences observed. ${ }^{6}$

In contrast to unipolar pacing, ${ }^{6}$ configuration differences during bipolar pacing were more common at higher current strength. As stimulus intensity increases, the anodal contribution to depolarization would be expected to increase (because of higher anodal thresholds), thereby shifting the effective central area of depolarization and producing larger configuration differences. A second potential explanation for a difference in pace maps at higher current strength could be the difference between the anisotropy of the extracellular medium and propagating impulses; ${ }^{13}$ however, with unipolar pacing ${ }^{6}$ we rarely observed stimulus intensity dependent differences in electrocardiograms, suggesting that this difference did not account for differences in the surface electrocardiogram. Even when pacing with a 5$\mathrm{mm}$ interelectrode distance at threshold, four of 29 patients had at least one lead that showed a configuration difference compared to unipolar pacing. Nineteen of 29 patients had at least one lead showing an amplitude difference between these two electrocardiograms.

These findings suggest that bipolar pacing has the potential to complicate the interpretation of pace maps. Since differences in amplitude and configuration between unipolar and bipolar pacing occur and are unpredictable, the degree of localization provided by bipolar pace-mapping will be less than with unipolar pace-mapping. A potential advantage of bipolar pacing is the smaller stimulus artifact, which could simplify analysis of the early portion of the QRS complex. However, when low current strengths were used, there was little difficulty in examining the onset of the QRS complex during unipolar pacing. We have previously shown that current strength has little effect on the QRS complexes resulting from unipolar pacing. ${ }^{6}$ Therefore, minimizing stimulus intensity during unipolar pace-mapping (to minimize the stimulus artifact) will not alter the QRS complex.

\section{Limitations}

A limitation of this study is that unipolar ventricular pacing was used to simulate a site of origin of ventricular tachycardia. Because reentry is the most common cause of ventricular tachycardia, pacing at a point source has an inherent limitation in simulating this arrhythmia. However, Miller et al., ${ }^{14}$ have demonstrated a "focal" origin of ventricular tachycardia (presumably due to microreentry) and pacing at a single site could simulate such a region or reproduce the exit site of a reentrant circuit such as a figure of 8 loop. ${ }^{15}$ Nonetheless, we cannot exclude the possibility that some cases of spontaneous ventricular tachycardia may have broad propagating wave fronts that proceed to stimulate the rest of the ventricles. In such cases, pacing at a point source might not be the most appropriate model to simulate the area of origin of ventricular tachycardia. However, Harris et al., ${ }^{16}$ examined activation patterns using a 220 site mapping technique and found that a monoregional spread of activation was the most common, and that a figure of 8 pattern with a single exit site the next most common pattern of impulse 
spread. Both these types of activation should be well modeled by unipolar pacing at a single site.

Although prior studies have examined anodal pacing thresholds and demonstrated that they are higher than cathodal thresholds, we did not measure anodal thresholds from the proximal electrode poles in this study. Finally, because of time constraints, pacing was performed at only one site per patient. Thus, there are inadequate data to compare pace maps obtained from different regions of the heart.

\section{Clinical Implications}

Careful examination of electrocardiograms obtained during unipolar pacing can usually localize an area of impulse origin to within $5 \mathrm{~mm}$. $^{6}$ However, bipolar pacing produces unpredictable differences in electrocardiogram configuration and amplitude when compared to unipolar pacing using the same distal electrode. These differences, which are most likely due to an anodal contribution, compromise the ability of bipolar pacemapping to precisely localize a site of impulse initiation because of the variable alteration in QRS configuration. Because precise localization may be crucial to the successful use of catheter ablation and other techniques, bipolar pace-mapping appears to be inferior to unipolar pace-mapping. ${ }^{2-5}$ Our results suggest that unipolar pace-mapping should be used as the pace-mapping method of choice in localizing ventricular tachycardia. If bipolar pacing is used to minimize the stimulus artifact or for convenience, the interelectrode distance should be small and the current intensity as low as possible to minimize the anodal contribution and provide better localization of the site of arrhythmia origin.

Acknowledgments: The authors would like to thank Lisa Stephens, Marion McGuire, and Veronica Jefferson for secretarial assistance, and Keith Childs for help in collating the pace-mapping data.

\section{References}

1. Josephson ME, Harken AH, Horowitz LN. Endocardial excision: A new surgical technique for the treatment of recurrent ventricular tachycardia. Circulation 1979; 60:1430-1439.

2. Morady F, Scheinman MM, DiCarlo LA Jr, et al. Catheter ablation of ventricular tachycardia with intracardiac shocks: Results in 33 patients. Circulation 1987; 75:1037-1049.
3. Brugada P, de Swart H, Smeets JLRM, et al. Transcoronary chemical ablation of ventricular tachycardia. Circulation 1989; 79:475-482.

4. Naccarelli GV, Kuck K-H, Pitha JV, et al. Catheter ablation of canine ventricular myocardium utilizing radiofrequency current. J Electrophysiol 1989; 3:223-232.

5. Josephson ME, Waxman HL, Cain ME, et al. Ventricular activation during ventricular endocardial pacing. II. Role of pace-mapping to localize origin of ventricular tachycardia. J Am Coll Cardiol 1982; 50:11-22.

6. Kadish AH, Childs K, Schmaltz S, et al. Differences in QRS configuration during unipolar pacing from adjacent sites: Implications for the spatial resolution of pace-mapping. J Am Coll Cardiol (In press) 1991.

7. Stevenson WG, Weiner I, Weiss JN, Contribution of the anode to ventricular excitation during bipolar programmed electrical stimulation. Am J Cardiol 1986; 57:582-586.

8. Kadish AH, Morady F, Rosenheck S, et al. The effect of electrode configuration on the unipolar Hisbundle electrogram. PACE 1989; 12:1445-1450.

9. Cassidy DM, Vassallo JA, Miller JM, et al. Endocardial catheter mapping in patients in sinus rhythm: Relationship to underlying heart disease and ventricular arrhythmias. Circulation 1986; 73:645-652.

10. Stevenson WG, Weiss JN, Wiener I, et al. Fractionated endocardial electrograms are associated with slow conduction in humans: Evidence from pace-mapping. J Am Coll Cardiol 1989; 13:369376.

11. Van Gelder LM, El Gamal MIH, Tielen CHJ. Changes in configuration of the paced QRS complex related to pacemaker output. PACE 1989; 12:1640-1649.

12. Dekker E. Direct current make and break thresholds for pacemaker electrodes on the canine ventricle. Circ Res 1970; 27:811-823.

13. Frazier DW, Krassowska W, Chen P, et al. Extracellular field required for excitation in three-dimensional anisotopic canine myocardium. Circ Res 1988; 63:147-164.

14. Miller JM, Harken AH, Hargrove WC. Pattern of endocardial activation during sustained ventricular tachycardia. J Am Coll Cardiol 1985; 6:12801287.

15. Mehra R, Zeiler R, Gough WB, et al. Reentrant ventricular arrhythmias in the late myocardial infarction period. 9. Electrophysiologic-anatomic correlation of reentrant circuits. Circ Res 1983; 67:1124.

16. Harris L, Downar E, Mickleborough L, et al. Activation sequence of ventricular tachycardia: Endocardial and epicardial mapping studies in the human ventricle. J Am Coll Cardiol 1987; 10:1040-1047. 
Copyright of Pacing \& Clinical Electrophysiology is the property of Blackwell Publishing Limited and its content may not be copied or emailed to multiple sites or posted to a listserv without the copyright holder's express written permission. However, users may print, download, or email articles for individual use. 